\title{
Relationship between Plasma Concentrations of Interleukin-10 and Thrombocytopenia in Chickenpox Patients
}

\author{
Mariam Al-Fadhli ${ }^{1}$, Mohammad Saraya ${ }^{2}$ \\ ${ }^{1}$ Department of Medicine, Infectious Disease Hospital, Ministry of Health, Kuwait. \\ ${ }^{2}$ Department of Tropical Medicine, Faculty of Medicine, Zagazig University, Egypt.
}

Corresponding Author

Mohammad Saraya

Mobile:

$+201000089246$

E. mail: mdsaraya@yahoo.com

Key words: interleukin-10 thrombocytopenia chickenpox
Background and study aim: Chickenpox is highly infectious, self-limiting disease, caused by varicella-zoster virus. Thrombocytopenia frequently complicates chickenpox. This study was conducted to assess the correlation between serum interleukin 10 levels and thrombocytopenia in adult chickenpox patients.

Patients and Methods: Fifty patients of chickenpox complicated by thrombocytopenia were included in this study as a patient group. Fifty patients of chickenpox with normal platelet of comparable age, race and gender were identified as a control group. All patients were diagnosed by clinical picture of chickenpox and by presence of varicella zoster virus immunoglobulin M (VZV $\operatorname{IgM})$ in the patient blood. Estimation of complete blood count, kidney function tests, liver function tests, fasting blood sugar, and levels of cytokines IL-10 and TNF- $\alpha$ were done in both groups on the day of admission and day of discharge.

Results: At time of admission, IL-10 levels were significantly higher in patients group than in control group, while TNF- $\alpha$ level were not significantly different between the two groups. At time of discharge, we observed a significant decline in IL-10 levels in the patients group as compared with time of admission. A negative correlation between IL-10 levels and platelet count was observed while no correlation was found between TNF- $\alpha$ and platelet count.

Conclusion: IL-10 level could play an important role in development of thrombocytopenia in patients with chickenpox.

\section{INTRODUCTION}

Chickenpox is highly infectious, selflimiting disease, caused by varicellazoster virus affecting all age groups associated with characteristic exanthematous vesicular skin rash and fever [1]. It can cause life-threatening complications especially in elderly, immune-compromised patients, smokers, or in pregnant women.

However, in recent years, some studies have shown that the incidence of chickenpox has doubled in adults and this has been paralleled with an increase in hospital admissions [2] and mortality [3]. The reason for this age shift is not known, though it may be the result of immigration of nonimmune adults from the tropics, decreased exposure to Varicella-Zoster virus (VZV), increasing vaccine coverage and this decrease in transmission can cause increase in susceptible adults followed by a shift of incidence into the older age group [4]. Furthermore, the clinical presentation of chickenpox in adults is severe as compared to children and more commonly associated with complications [5].

Chickenpox may be associated with serious complications particularly in adults and in immune-compromised patients [6]. The complication rate has been reported variably; the most frequent complications are secondary bacterial skin infection, varicella pneumonia, cerebellar ataxia, and subclinical hepatitis. Whereas, the rare complications are encephalitis, rhabdomyolysis, acute myocarditis, acute liver failure, acute pancreatitis, glomerulonephritis, and disseminated intra-vascular coagulation (DIC) [7]. 
Thrombocytopenia is considered a frequent hematological complication of chickenpox and it is four times more common in adults than children [8]. Varicella associated thrombocytopenia is well described in number of observational studies but mechanisms involved in thrombocytopenia are not well known, during the acute inflammatory response to chickenpox, the released cytokines play an important role in the pathogenesis of platelet reduction. To our knowledge, there is no studies have focused on the association of IL-10 and thrombocytopenia in chickenpox [8]. The aim of this study was to assess the potential correlation of serum interleukin 10 levels in the pathogenesis of thrombocytopenia in adult chickenpox patients admitted in the hospital.

\section{PATIENTS AND METHODS}

\section{Study design and the participants:}

This study was conducted between December 2014 and December 2015, at the Infectious Disease Hospital (IDH), Kuwait, which is a tertiary care hospital and accredited by the national Canadian accreditation program at 2014. A total of fifty patients of chickenpox complicated by thrombocytopenia were included in this study as patients group. Of the patients included in the study, 35 were Indian, 3 were Indonesian, 5 were Bangladeshi, 4 were Sri Lankan and 3 were Kuwaiti. In addition, fifty patients of chickenpox with normal platelet of comparable age, race and gender were identified as controls.

Diagnosis of chickenpox was based on the presence of a typical rash associated with fever and throat pain and serological confirmation was based on the presence of VZV IgM in the patient blood.

\section{Exclusion criteria :}

Patients with history of recent intake of drugs/ conditions which might cause thrombocytopenia, blood disorders, chronic liver disease, immunecompromised status (HIV/immunosuppressive drugs), active alcohol consumers and pregnant were excluded from the study.

\section{Data collection :}

Both groups were submitted to full history taking, comprehensive clinical examination, complete blood count, kidney function test, liver function test, fasting blood sugar, and levels of cytokines interleukin-10 (IL-10) and tumor necrosis factor- $\alpha$ (TNF- $\alpha$ ) (Biomedix medical group, Synlab, German).

Thrombocytopenia was defined if platelet count was less than $150 \times 10^{3} / \mathrm{ul}$ (Ref.range:150400x103/ul) [9]. According to National Cancer Institute (NCI) Criteria for Adverse Events Version 3 [10], thrombocytopenia has been graded into the following:

Grade 0: Within normal limit, platelet count 150,000 or above.

Grade I: Platelet count between 75,000 and 150,000.

Grade II: Platelet count between 50,000 and 75,000 .

Grade III: Platelet count between 25,000 and 50,000

Grade IV: Platelet count less than 25,000.

The treatment of chickenpox and its complications was done as per standard guidelines. All patients received acyclovir intravenously or orally in proper dose according to body weight for 5 to 7 days [11]. Platelet count was repeated on every other day and patients were discharged from the hospital once the patients became asymptomatic and the platelet count returned to the reference range.

\section{Statistical analysis :}

The statistical package for social sciences (SPSS) version 8.0 software was used for analysis the data. The t-test was used to evaluate the significance of differences between mean values of the study variables. The significance of differences between proportions was performed using the Chi-square test. Significant differences were expressed at $\mathrm{P}<0.05$.

\section{RESULTS}

In this study, 50 patients with chickenpox complicated by thrombocytopenia were included. The mean age \pm SD of the patients under the study was $31.12 \pm 6.25$ years and males outnumbered the females $40(80 \%)$ vs. $10(20 \%)$ with different grading of thrombocytopenia. There was no statistically significant difference in the means of age among the two groups (Table 1). All the patients had fever $(100 \%)$ at the time of presentation, followed by Pleomorphic itchy skin rash $(100 \%)$, nausea $(40 \%)$, vomiting $(40 \%)$, anorexia $(60 \%)$, diarrhea $(05 \%)$, abdominal pain $(10 \%)$, cough $(14 \%)$ and breathlessness $(08 \%)$. 
Out of 50 cases in patients group, $26(52 \%)$ cases had Grade I thrombocytopenia, 14 (28\%) cases had Grade II thrombocytopenia, 8 (16\%) cases had Grade III thrombocytopenia and 2 (4\%) cases had Grade IV thrombocytopenia (Table 2). None of the patients with thrombocytopenia developed purpuric spot, ecchymosis or bleeding manifestation during the course of disease.

At time of admission, mean platelet count was $101.84 \pm 40.2$ and a significant difference was noted between the studied groups. While mean hemoglobin value was $12.3 \pm 1.8$ and mean white blood cell count was $7.8 \pm 1.5$ and there were not significantly different between the two groups (Table 1). Higher significantly differences were observed in IL-10 levels in patients group as compared with control group (mean serum IL-10 levels of $13.7 \pm 1.8$ vs. $6.9 \pm 0.8, \mathrm{P}<0.001)$. It has been further observed that there was no significant deference as regard pro-inflammatory cytokine TNF- $\alpha$ in patients group when compared with controls. There were significant differences between the studied groups as regard liver enzymes alanine transaminase and aspartate transaminase (Table 1).

At time of discharge, we observed a significant decline in IL-10 levels in the patients group as compared with time of admission (mean serum IL-10 levels of $13.7 \pm 1.8$ vs. $7.46 \pm 1.02, \mathrm{P}<0.001$ ). Also, at time of discharge, there was significant increase in number of platelet in patients group as compared with time of admission (mean platelet count was $152.73 \pm 34.46$ vs. $101.84 \pm$ 40.2, $\mathrm{P}<0.05)$ and Platelet was still significant low in patients group as compared with controls (Table 3).

In this study, a negative correlation between IL10 levels and platelet count was observed. While no correlation was found between pro-inflammatory cytokine TNF- $\alpha$ and platelet count (Table 4).

Table (1) : Comparison between studied groups at time of admission

\begin{tabular}{|c|c|c|c|}
\hline \multirow{2}{*}{} & \multicolumn{3}{|c|}{ On admission } \\
\cline { 2 - 4 } & patients group & control group & P-value \\
\hline Age & $31.12 \pm 6.25$ & $30.23 \pm 5.67$ & 0.82 \\
\hline ALT & $144.13 \pm 34.28 \mathrm{u} / \mathrm{L}$ & $81.90 \pm 8.86 \mathrm{u} / \mathrm{L}$ & 0.01 \\
\hline AST & $113.0 \pm 24.61 \mathrm{u} / \mathrm{L}$ & $67.8 \pm 4.47 \mathrm{u} / \mathrm{L}$ & 0.01 \\
\hline IL-10 & $13.7 \pm 1.8$ & $6.9 \pm 0.8$ & 0.001 \\
\hline TNF- $\alpha$ & $6.2 \pm 1.5$ & $5.1 \pm 1.2$ & 0.11 \\
\hline Platelet & $101.84 \pm 40.210^{3} / \mathrm{uL}$ & $211.85 \pm 45.510^{3} / \mathrm{uL}$ & 0.001 \\
\hline WBCs & $7.8 \pm 1.510^{3} / \mathrm{uL}$ & $7.34 \pm 1.2410^{3} / \mathrm{uL}$ & 0.72 \\
\hline Hemoglobin & $12.3 \pm 1.8 \mathrm{~g} / \mathrm{dL}$ & $13.1 \pm 2.2 \mathrm{~g} / \mathrm{dL}$ & 0.51 \\
\hline S. creatinine & $99.57 \pm 13.02 \mu \mathrm{mol} / \mathrm{L}$ & $91.45 \pm 13.23 \mu \mathrm{mol} / \mathrm{L}$ & 0.21 \\
\hline
\end{tabular}

TNF- $\alpha$ : tumor necrosis factor alpha; AST: aspartate transaminase;
IL-10: interleukin-10;

WBCs: White blood cells;
ALT: alanine transaminase

SC: serum creatinine

Table (2) : Distribution of sex as regard grading of thrombocytopenia

\begin{tabular}{|c|c|c|c|}
\hline & Male (\%) & Female (\%) & Total \\
\hline Grade 0 & $0(0.0)$ & $0(0.0)$ & 0 \\
\hline Grade I & $20(76.9)$ & $6(23.1)$ & 26 \\
\hline Grade II & $11(78.5)$ & $3(21.5)$ & 14 \\
\hline Grade III & $7(87.5)$ & $1(12.5)$ & 8 \\
\hline Grade IV & $2(100.0)$ & $0(0.0)$ & 2 \\
\hline Total & $40(80.0)$ & $10(20.0)$ & 50 \\
\hline
\end{tabular}


Table (3): Comparison between studied groups at time of discharge

\begin{tabular}{|c|c|c|c|}
\hline \multirow{2}{*}{ ALT } & \multicolumn{3}{|c|}{ On discharge } \\
\cline { 2 - 4 } & Patients group & Control group & P-value \\
\hline AST & $50.35 \pm 10.03$ & $49.71 \pm 9.26$ & 0.62 \\
\hline IL-10 & $38.7 \pm 5.92$ & $37.95 \pm 6.78$ & 0.71 \\
\hline TNF- $\boldsymbol{\alpha}$ & $7.46 \pm 1.02$ & $4.14 \pm 0.9$ & 0.018 \\
\hline Platelet & $5.9 \pm 0.9$ & $6.01 \pm 1.01$ & 0.94 \\
\hline WBCs & $152.73 \pm 34.46$ & $243.10 \pm 33.34$ & 0.01 \\
\hline Hemoglobin & $8.42 \pm 1.63$ & $8.39 \pm 1.67$ & 0.95 \\
\hline S. creatinine & $13.5 \pm 2.1$ & $13.9 \pm 1.9$ & 0.91 \\
\hline
\end{tabular}

Table (4): Correlation between serum IL10 levels, TNF $\alpha$, and other parameters in studied groups

\begin{tabular}{|c|c|c|c|c|c|c|c|c|}
\hline & \multicolumn{4}{|c|}{ IL-10 } & \multicolumn{4}{c|}{ TNF- $\boldsymbol{c}$} \\
\cline { 2 - 9 } & Patient Group & \multicolumn{2}{c|}{ Control Group } & \multicolumn{2}{c|}{ Patient Group } & \multicolumn{1}{c|}{ Control Group } \\
\cline { 2 - 9 } & $\mathbf{R}$ & $\mathbf{p}$ & $\mathbf{R}$ & $\mathbf{p}$ & $\mathbf{R}$ & $\mathbf{p}$ & $\mathbf{r}$ & $\mathbf{P}$ \\
\hline \multirow{2}{*}{ Age } & -0.02 & 0.944 & -0.01 & 0.96 & 0.19 & 0.48 & 0.06 & 0.81 \\
& & NS & & NS & & NS & & NS \\
\hline ALT & 0.29 & 0.1 & 0.05 & 0.24 & -0.27 & 0.25 & 0.03 & 0.68 \\
& & NS & & NS & & NS & & NS \\
\hline AST & 0.25 & 0.41 & 0.44 & 0.09 & -0.23 & 0.404 & 0.22 & 0.43 \\
& & NS & & NS & & NS & & NS \\
\hline Platelet & $-0.52^{*}$ & $<0.05$ & 0.43 & 0.104 & -0.32 & 0.25 & 0.11 & 0.68 \\
& & $\mathbf{S}$ & & NS & & NS & & NS \\
\hline IL-10 & 1.000 & 0 & 1.000 & 0 & 0.19 & 0.49 & 0.31 & 0.52 \\
& & & & & & NS & & NS \\
\hline TNF- $\alpha$ & 0.19 & 0.49 & 0.31 & 0.52 & 1.000 & 0 & 1.000 & 0 \\
& & NS & & NS & & & & \\
\hline
\end{tabular}

\section{DISCUSSION}

Chickenpox infection is frequently complicated by thrombocytopenia; however, hemorrhagic manifestations are rare [12]. Some of observational studies have addressed the correlation of thrombocytopenia to chickenpox [8]. Thrombocytopenia in chickenpox infection usually develops early in the course of the disease.The frequency of thrombocytopenia in chickenpox patients has been reported as $1 \%$, $22.5 \%, 30 \%$ and $45 \%$ in various studies $[12,13,14,15]$. The mechanisms involved in thrombocytopenia are not well identified [8], Two likely pathogenetic mechanisms are suggested: Both immunological and nonimmunological destruction of platelets have been implicated in causing platelet reduction. Non immunological mechanism is the infectious one with platelet reduction during the period of viremia: the other immunological pathogenesis is post infectious with thrombocytopenia continuing for weeks and months [16]. IgM and IgG antiplatelet antibodies on platelets have been identified, suggesting involvement of immune mediated mechanisms [16]. Thrombocytopenia may be detectable before appearance the characteristic rash, suggesting direct destruction of platelets. Immune thrombocytopenia (ITP) is a rare complication of chickenpox which appears as a delayed complication [17].

During an acute inflammatory response to chickenpox infection, the released cytokines play a role in the mechanism of platelet reduction [18]. The present study revealed significant higher levels of IL-10 in patients group at time of admission. Jenkins et al. has demonstrated that the induction of specific $\mathrm{T}$ cells to VZV and IgG antibodies production was associated by transient increases in IL-10 production [19]. There is no previous reports have focused on the correlation between IL-10 and platelet reduction in chickenpox infection. Here, the present study revealed that thrombocytopenia in adult with 
chickenpox is negatively correlated with serum concentrations of IL-10. There is evidence that IL-10 may play a role directly in induction of thrombocytopenia. The administration of a low dose of recombinant human IL-10 $(8 \mu \mathrm{g} / \mathrm{kg} / \mathrm{d})$ decreased platelet production in healthy adult volunteers [18]. In the same study, there was a corresponding reduction in splenic sequestration of platelets in the IL-10 treated group compared with the placebo treated subjects. There was a trend toward lower numbers of megakaryocyte colony-forming units (CFU-MKs) in the IL-10 treated group compared with volunteers who received placebo [18]. This study suggests that IL-10 induced reduction in platelet count is caused, at least in part, by a reduction in platelet production.

Tumor necrosis factor- $\alpha$ has been accompanied with platelet consumption in mice [20], but in this study, we could not demonstrate an association between thrombocytopenia and plasma concentration of TNF- $\alpha$, suggesting but not unequivocally that TNF- $\alpha$ does not have a significant role in the evolution of thrombocytopenia in patients with chickenpox infection.

\section{CONCLUSION}

Thrombocytopenia is frequently associated with chickenpox. Furthermore, thrombocytopenia in chickenpox usually does not cause bleeding tendency and the platelet count improves with the treatment of chickenpox. Plasma concentration of IL-10 was negatively correlated with platelet count. IL-10 induced reduction in platelet count is caused, at least in part, by a reduction in platelet production.

\section{Funding: None.}

Conflicts of interest: None.

Ethical approval:Approved.

\section{REFERENCES}

1- Gregorakos L, Myrianthefs P, Parkou N. Severity of illness and outcome in adult patients with primary varicella pneumonia. Respiration 2002; 69: 330334.

2- Wilkens EG, Leen CL, Mc Kendrick MW, Carrington D. Management of chickenpox in adults. J Infec 1998; 1: 49-48.

3- Rawson H, Crampian A, Noah N. Deaths from chickenpox in England and Wales 1995-7: analysis of routine mortality data. BMJ 2001; 323: 1091-3.

4- Waller TH. Varicella: Historical perspectives and clinical overview. J Infec Dis 1996; 174: 306-9.
5- Jones AM, Thomas N, Wilkins EGL. Outcome of varicella pneumonitis in immunocompetent adults requiring treatment in a high dependency unit. J Infect 2001; 43: 135-9.

6- Kumar S, Jain AP, Pandit AK. Acute pancreatitis: Rare complication of Chickenpox in an immunocompetent host. Saudi J Gastroentrol 2007; 13: 138-40.

7- Alborzi P. Chickenpox in adults. SEMJ 2001; 2(3):167-170.

8- Abro AH, Ustadi AM, Gangwani JL, Abdou AMS, Chandra FS, Al-Haj A. Varicella induced thrombocytopenia in adults. Pak J Med Sci 2009; 25(1):7-11.

9- Craig JIO, McClelland DBL, Ludlam CA. In: Davidson's Principles and Practice of Medicine. Blood disorders. 20th Ed: Churchill Livingstone 2006; 1011.

10- Bethesda: U.S Department of Health and Human Services; 2006; National Cancer Institute Criteria for Adverse Events Version 3; p. 4.

11- Marcelo Cordeiro dos Santos and Maria G. Costa Alecrim: Varicella Pneumonia in an Adult. $N$ Engl J Med; 2010; 362:1227.

12- Nadir A, Masood A, Irfan Majeed, Waheed uz Zaman T. Chickenpox associated thrombocytopenia in adults. J Coll Physician Surg Pak 2006;16 (4):270-2.

13- Anne G. Varicella and Herpes zoster: Clinical disease and complications. Herpes 2006; 13:27A.

14- Rivest P, Bedard L, Valiquette L, Mills E, Lebel $\mathrm{MH}$, Lavoie G, et al. Severe complications associated with varicella: Province of Quebec, April 1994-March 1996. Can J Infect Dis Med Microbiol 2001; 12:21-6.

15- Tucci PL, Tucci F, Peruzzi PF. The behavior of platelets in some viral diseases in childhood. Ann Sclavo 1980;22:431-7.

16- Ali Hassan Abro, Abdulla M Ustadi, Jawahar L. Gangwani, Ahmed MS Abdou, Fatma Saifuddin Chandra, Abeer Al-Haj. Varicella induced thrombocytopenia in adults. Pak J Med Sci January - March 2009; Vol. 25 No. 1 7-11.

17- Kaneda K, Koijima K, Shinagawa K, Ishimura F, Ikeda K, Niiya K, et al. An adult patient with varicella preceded by acute thrombocytopenia. Rinsho Katsueki 2001;42:1142-4.

18- Jennifer P. Wang ,Evelyn A. Kurt-Jones, Ok S. Shin, Michael D. Manchak, Myron J. Levin, and Robert W. Finberg. Varicella-Zoster Virus Activates Inflammatory Cytokines in Human Monocytes and Macrophages via Toll-Like Receptor 2. J. Virol. October 2005; vol. 79 no. 20, 12658-12666.

19- Jenkins DE1, Redman RL, Lam EM, Liu C, Lin I, Arvin AM. Interleukin (IL)-10, IL-12, and interferon-gamma production in primary and memory immune responses to varicella-zoster virus. J Infect Dis. 1998 Oct;178(4):940-8. 
20- Tacchini-Cottier F, Vesin C, Redard M, Buurman $\mathrm{W}$, Piguet PF,. Role of TNFR1 and TNFR2 in TNF-induced platelet consumption in mice. $J$ Immunol. 1998;160: 6182-6186.

Peer reviewers: Sahar El-Nemr, Professor of Tropical Medicine, Faculty of Medicine, Zagazig University, Egypt.Noha Shaheen Assistant
Professor of Tropical Medicine, Faculty of Medicine, Zagazig University, Egypt.

Editors: Tarik Zaher , Professor of Tropical Medicine , Faculty of Medicine, Zagazig University, Egypt. 